\title{
Inhibition of NADPH oxidase activity promotes differentiation of B16 melanoma cells
}

\author{
YUNFENG ZHAO, JIANFENG LIU and KENNETH E. McMARTIN
}

\author{
Department of Pharmacology, Toxicology and Neuroscience, LSU Health Sciences Center, Shreveport, LA 71130, USA
}

Received June 5, 2007; Accepted September 20, 2007

\begin{abstract}
The activity of NADPH oxidase is increased in malignant skin keratinocytes. We demonstrated that inhibition of NADPH oxidase activity by diphenyleneiodonium (DPI) suppressed free radical production, inhibited cell growth and promoted cell differentiation of B16 melanoma cells, as indicated by cell morphology, increased production of melanin, and increased expression of microphthalmiaassociated transcription factor (MITF). siRNA to NADPH oxidase subunit Rac1 or p47 induced the expression of MITF, verifying that the pro-differentiation effects are due to the inhibition of NADPH oxidase. Biochemical studies suggest that ERK plays a positive role whereas PKC $\alpha$ plays a negative role during this differentiation event. In addition, the protein levels of the tumor suppressor p53 were suppressed by DPI, suggesting that $\mathrm{p} 53$ is activated by oxidative stress and may negatively regulate differentiation in melanoma cells. Taken together, these results suggest that inhibiting NADPH oxidase activity promotes cell differentiation of B 16 melanoma cells.
\end{abstract}

\section{Introduction}

Reactive oxygen species (ROS) are powerful oxidants that are toxic to cells at high concentrations, but act as intracellular second messengers at sublethal concentrations, leading to transcriptional activation of various genes for cell survival and proliferation. Consistently, cancer cells are lower in antioxidant

Correspondence to: Dr Yunfeng Zhao, Department of Pharmacology, Toxicology and Neuroscience, LSU Health Sciences Center-Shreveport, Shreveport, LA 71130, USA

E-mail: yzhao1@1suhsc.edu

Abbreviations: DPI, diphenyleneiodonium; DMSO, dimethylsulfoxide; ERK, extracellular signal regulated kinase; GAPDH, glyceraldehyde-3-phosphate dehydrogenase; MITF, microphthalmiaassociated transcription factor; MnSOD, manganese superoxide dismutase; NOX, NADPH oxidase; PBS, phosphate buffered saline; PCNA, proliferating cell nuclear antigen; PKC, protein kinase C; PTEN, phosphatase and tensin homolog deleted on chromosome ten; ROS, reactive oxygen species

Key words: melanoma, differentiation, oxidative stress, NADPH oxidase enzyme levels, and elevation of the levels of these enzymes is able to reduce tumorigenicity (1).

Melanoma is the most aggressive form of skin cancer. In the United States, its incidence is rapidly increasing, especially in the $<35$-year-old population (2). Early diagnosis and prompt surgical removal leads to a high cure rate. However, if it reaches the vertical growth phase, melanoma tends to be aggressive and metastasizes. At this stage, there is little effective chemotherapy for melanoma (2).

Malignant melanoma cells spontaneously generate reactive oxygen species (ROS) that promote a constitutive activation of the transcription factors such as NF- $\mathrm{kB}$. The nature of the enzyme responsible for ROS production in melanoma cells has been studied (3). ROS are generated by isolated, cytosol-free melanoma plasma membranes, with inhibition by NADPH oxidase inhibitor diphenyleneiodonium (DPI).

We previously demonstrated that the activity of NADPH oxidase was increased after the tumor promoter 12-Otetradecanoylphorbol-13-acetate (TPA) treatment in skin keratinocyte 308 cells (4). The inhibition of its activity by DPI led to the suppression of oxidative stress and of the subsequent cell proliferation induced by TPA in both skin cells and skin epidermal tissues, suggesting that NADPH oxidase could serve as a potential target for skin cancer prevention and/or treatment. We tested this hypothesis in well-used and genetically stable B16 melanoma cells.

\section{Materials and methods}

Cell line and reagents. Murine melanoma B16-F10 cells were grown in Dulbecco's modified Eagle's medium (Invitrogen, Carlsbad, CA) supplemented with $10 \%$ fetal bovine serum (Hyclone Laboratories Inc., Logan, UT), $5 \mathrm{U} / \mathrm{ml}$ penicillin and $5 \mu \mathrm{g} / \mathrm{ml}$ streptomycin, at $37^{\circ} \mathrm{C}$ in $5 \% \mathrm{CO}_{2}$.

Ten millimolar diphenyleneiodonium (DPI, Sigma, St. Louis, MO) stock solutions in dimethylsulfoxide (DMSO, Sigma) were prepared. DPI was diluted in a culture medium for the treatment of cells. DMSO $(0.01 \%)$ diluted in the medium was used as the Vehicle control. PD98059 was purchased from Cayman (Ann Arbor, MI) and dissolved in DMSO at a concentration of $20 \mathrm{mM}$.

Detection of ROS. The intracellular production of ROS was assayed using DCFH-DA or dihydrorhodamine 123 as a substrate. Briefly, 5,000 cells were seeded in a 96-well plate and incubated overnight. The following day, the medium was replaced with a fresh medium, and cells were treated with 
three concentrations of DPI $(0.5,1$ and $2 \mu \mathrm{M})$ for $24 \mathrm{~h}$. DMSO $(0.01 \%)$ was added as the Vehicle control. Cells were washed with PBS (pH 7.4) and incubated with a fresh medium containing $10 \mu \mathrm{M}$ DCFH-DA or dihydrorhodamine 123 (Molecular Probes, Eugene, OR) for $15 \mathrm{~min}$ at $37^{\circ} \mathrm{C}$. DCFHDA was oxidized by ROS to the highly fluorescent $2^{\prime}, 7^{\prime}-$ dichlorofluorescein (DCF); dihydrorhodamine 123 was oxidized to fluorescent rhodamine. The fluorescence was then read at excitation/emission of $488 / 525 \mathrm{~nm}$ for DCF or $507 / 529 \mathrm{~nm}$ for rhodamine with a Spectra max gemini plate reader from Molecular Devices. The fluorescence from cells only (no dye added) was used to subtract the sample value from each corresponding well.

NADPH oxidase activity assay. This assay was performed as previously described by Cui and Douglas (5). Cells were collected and re-suspended in a buffer containing $20 \mathrm{mM}$ $\mathrm{KH}_{2} \mathrm{PO}_{4}, 1 \mathrm{mM}$ EGTA, $10 \mu \mathrm{g} / \mathrm{ml}$ aprotinin, $25 \mu \mathrm{g} / \mathrm{ml}$ leupeptin, and $1 \mathrm{mM}$ phenylmethylsulfonyl fluoride. The cell suspension was homogenized with 50 strokes in a Dounce homogenizer on ice, and aliquots of the homogenate were used immediately. To start the assay in a 96-well plate, $10 \mu 1$ of homogenate was added into $90 \mu 1$ of $50 \mathrm{mM}$ phosphate buffer, pH 7.0, containing $1 \mathrm{mM}$ EGTA, $150 \mathrm{mM}$ sucrose, $500 \mu \mathrm{M}$ luciginin, and $100 \mu \mathrm{M}$ NADPH. Photoemission in terms of relative luminescence units (RLU) was measured every minute for a 15 -min period using the Lucy2 microplate reader (Rosys Anthros Labtec Instruments, Austria).

Measurement of total melanin. The experiments were performed following the protocols described previously (6) with slight modifications. After $1 \times 10^{6}$ cells had been seeded in p100 dishes and cultured for $24 \mathrm{~h}$, cells were treated with four doses of DPI and Vehicle control (0.01\% DMSO) for $24 \mathrm{~h}$. Cells were collected by centrifugation at $750 \mathrm{x} \mathrm{g}, 4^{\circ} \mathrm{C}$, for $10 \mathrm{~min}$. The cell pellet was resuspended in $1 \mathrm{ml}$ of alkaline solution (1 $\mathrm{M} \mathrm{NaOH}$ in $10 \% \mathrm{DMSO}$ ) and incubated at $80^{\circ} \mathrm{C}$ for $2 \mathrm{~h}$. After centrifugation at $500 \mathrm{x} \mathrm{g}$ for $10 \mathrm{~min}$, the protein concentration and melanin in the remaining supernatant were measured. The amount of melanin was determined with a Multiskan microplate reader (MTX Lab Systems, Inc. Vienna, VA) at $490 \mathrm{~nm}$ using synthetic melanin (Sigma) as a standard.

Preparation of whole cell lysate. B16 cells were scraped from the plate into PBS, followed by centrifugation. The pellet was re-suspended in $100 \mu \mathrm{l}$ of homogenization buffer $(20 \mathrm{mM}$ HEPES, pH 7.0, 5 mM EGTA, $10 \mathrm{mM}$ 2-mercaptoethanol, $1 \mathrm{mM}$ PMSF, $1 \mu \mathrm{g} / \mathrm{ml}$ leupeptin, $1 \mu \mathrm{g} / \mathrm{ml}$ aprotinin, and $1 \mu \mathrm{g} /$ $\mathrm{ml}$ pepstatin). Cells were then sonicated (using a Fisher 550 sonicator) for $10 \mathrm{sec}$ on ice at $40 \%$ scale. The lysate was centrifuged $(50 \mathrm{x} \mathrm{g}$ or $600 \mathrm{rpm}$ for $5 \mathrm{~min}$ ) to remove cell debris; the resulting supernatant was designated as a whole cell lysate and kept at $-80^{\circ} \mathrm{C}$.

Rac1/p47 knockdown by the siRNA approach. siRNA to Rac1 or p47 was purchased from Millipore (Billerica, MA) or Santa Cruz Biotechnology (Santa Cruz, CA), respectively. B16 cells $\left(1 \times 10^{5}\right)$ were seeded in a 6-well plate and incubated overnight. siRNA $(10 \mu 1)$ to Rac1 or p47 and the control siRNA were mixed with siRNA transfection reagent and medium (Santa Cruz), and transfection was conducted following the procedures provided by the manufacturer. After being transfected for $48 \mathrm{~h}$, cells were collected and processed for Western blot analysis.

Western blot analysis. For detecting the protein levels of MITF, PCNA, (p) PKC $\alpha$, pERK, p53, PTEN and GAPDH (serving as a loading control), $30 \mu \mathrm{g}$ of the whole cell lysate was separated on $10 \%$ SDS-PAGE gels and transferred to a nitrocellulose membrane. Antibodies against MITF, PCNA, (p) PKC $\alpha, p E R K$, and PTEN were purchased from Santa Cruz Biotechnology (Santa Cruz). Anti-p53 antibody (Ab-11) was purchased from Calbiochem (San Diego, CA). For each set of data, the experiments were repeated three times and representative images were shown.

Statistical analysis. Statistical analysis was performed using one-way ANOVA (for multiple group comparison) followed by the Newman-Keuls post-test. Data are reported as mean \pm standard error (SEM). $\mathrm{P}<0.05$ is considered to be significantly different.

\section{Results}

Inhibition of NADPH oxidase promoted cell differentiation of B16 melanoma cells. Previously, we demonstrated that NADPH oxidase (NOX) is a critical mediator of the tumor promoter TPA-induced oxidative stress in malignant skin keratinocyte 308 cells (4). In order to study the role of NOX in generating reactive oxygen species (ROS) in B16 melanoma cells, we treated B16 cells with three concentrations of DPI and then measured DCF and rhodamine fluorescence as indicators of ROS levels. As seen in Fig. 1A, all three concentrations of DPI significantly reduced the levels of DCF and rhodamine fluorescence even after $24 \mathrm{~h}$ of treatment. To confirm that NOX was a target of DPI, we measured its enzymatic activity; a representative result is shown in Fig. 1B. There were significant levels of NOX activity in the Vehicle (0.01\% DMSO)-treated sample, whereas all three concentrations of DPI inhibited its activity to very low levels. Since suppression of oxidative stress by elevation of the levels of manganese superoxide dismutase (MnSOD) has been shown to inhibit cell proliferation and promote cell differentiation in C3H10T1/2 cells (7) and fibrosarcoma FSa-II cells (8), we measured the levels of melanin and microphthalmia-associated transcription factor (MITF), and observed cell morphology as markers for cell differentiation of B16 melanoma cells. As shown in Fig. 1C, we detected increases in melanin production in all three concentrations of DPI after a 24-h treatment, suggesting that the inhibition of NOX activity could promote cell differentiation of B 16 melanoma cells. MITF is responsible for the differentiation of melanocytes; Western blot analysis showed an increased expression of MITF after DPI treatment for $24 \mathrm{~h}$ (Fig. 1D). We then chose the concentration of $1 \mu \mathrm{M}$ DPI and treated B16 cells for a period of six days. As seen in Fig. 1E, starting at Day 3, B16 cells showed enlargement and dendrite-like structures; coincidently, cell proliferation was suppressed by DPI treatment (Fig. 1F). These results further confirm the pro-cell differentiation and anti-cell proliferation effects that 
A
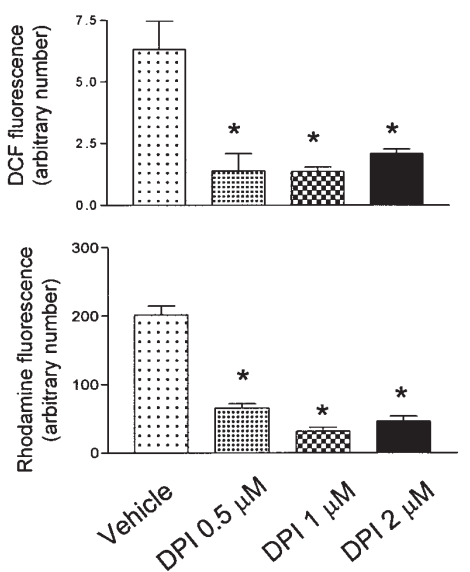

C

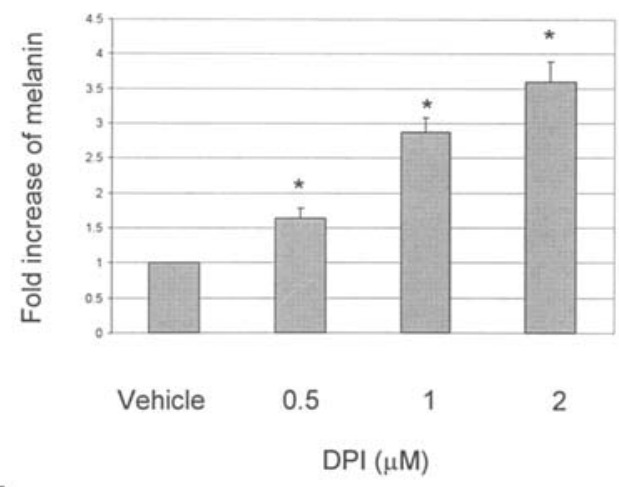

E

Vehicle

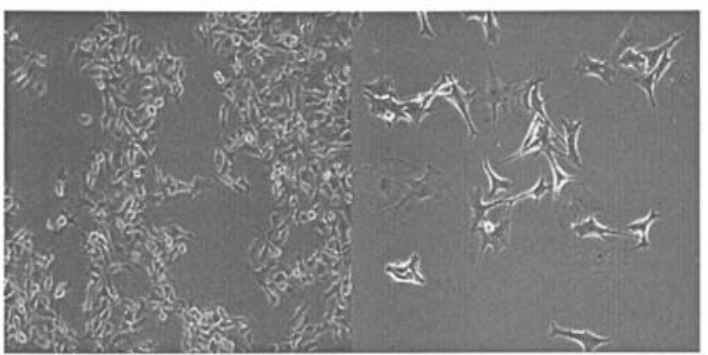

B

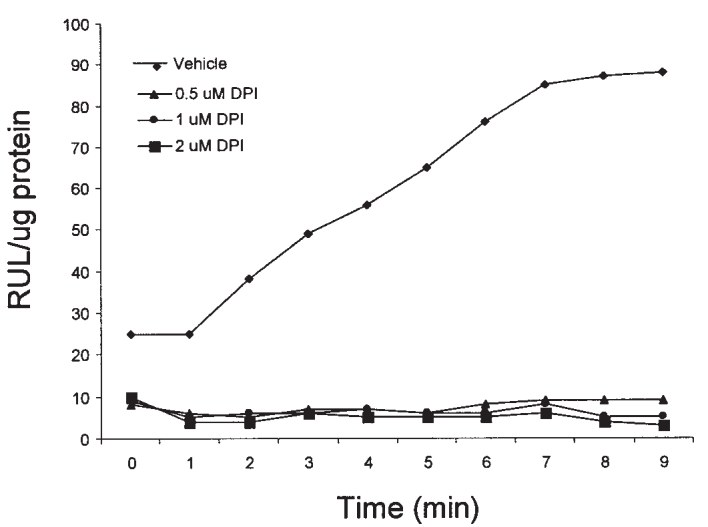

D

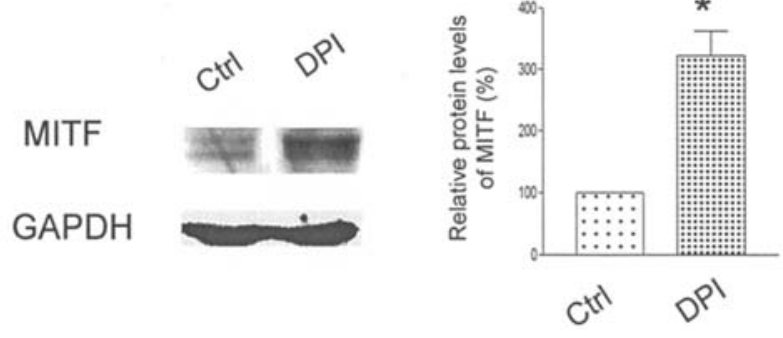

$\mathbf{F}$

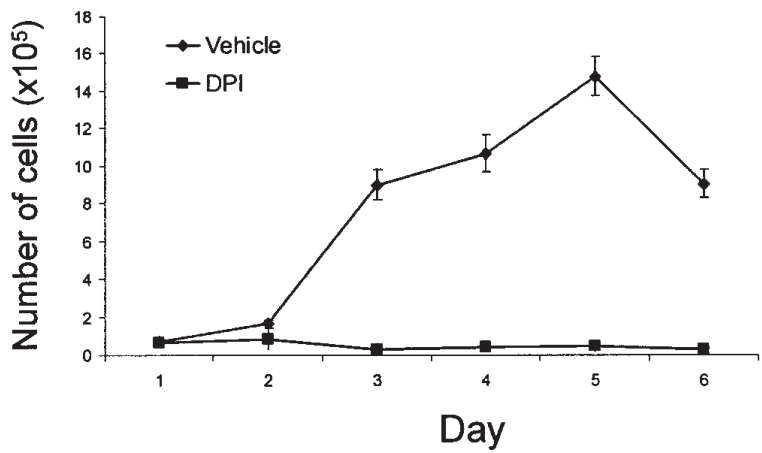

Figure 1. Inhibition of NOX activity suppressed cell growth and promoted cell differentiation in melanoma B16 cells. (A) Effects on ROS generation by DPI treatment. Melanoma B16 cells were treated with three concentrations of DPI for $24 \mathrm{~h}$. Fluorescent intensity of DCF and rhodamine in each sample was recorded and plotted. (B) Effects on NOX activity by DPI treatment. A representative result is shown. Three concentrations of DPI were used for the studies. Luciginin was used as a substrate of NOX. (C) Quantitative analysis of melanin production after treatment with three concentrations of DPI for 24 h. The levels of melanin were determined using a melanin standard. (D) Western blot analysis of MITF. B16 cells were treated with $1 \mu \mathrm{M}$ DPI for $24 \mathrm{~h}$. (E) Morphology of B16 cells after treatment with $1 \mu \mathrm{M}$ DPI for 3 days. Cells were visualized using a phase contrast microscopy, a representative image is shown. Cells $\left(2 \times 10^{4}\right)$ were seeded in p60 plates. The following day, cells were treated with either $1 \mu \mathrm{M}$ DPI or vehicle (x10 magnification). (F) Growth curve of B16 cells. Cells $\left(2 \times 10^{4}\right)$ were seeded in p60 plates. The next day, cells were treated with either $1 \mu \mathrm{M}$ DPI or vehicle. Cells were counted everyday for a 6 -day period. All the experiments were repeated at least three times. DMSO $(0.01 \%)$ was used as a Vehicle control. For Fig. 1A, B and C, DPI was treated when cell growth reached $\sim 60 \%$ confluency. ${ }^{*}$ Significant difference compared with Vehicle control, $\mathrm{p}<0.05$.

occur by inhibiting NOX activity. The latter effect is not due to increased apoptosis, because in $1 \mu \mathrm{M}$ DPI treated (for 24 and $48 \mathrm{~h}$ ) samples, the percentage of apoptotic cells was even less than the vehicle-treated (0.01\% DMSO) samples, as detected by both Annexin V staining and Cell death ELISA (data not shown).

To verify the specificity of inhibiting NADPH oxidase in the cell differentiation events, we decreased the expression of NADPH oxidase subunit Rac1 or p47 using the siRNA approach. Western blot analysis demonstrated that inhibition of the expression of either NADPH oxidase subunit increased the levels of MITF, while the control siRNA had no effect on MITF expression (Fig. 2A and B).

PKC $\alpha$ expression was decreased whereas ERK was activated by the inhibition of NADPH oxidase activity. For mechanistic studies, we treated B16 cells with $1 \mu \mathrm{M}$ DPI and prepared whole cell lysates. We detected the protein levels of PCNA 
A

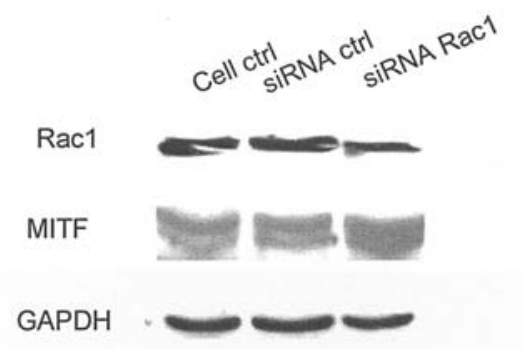

Rac1

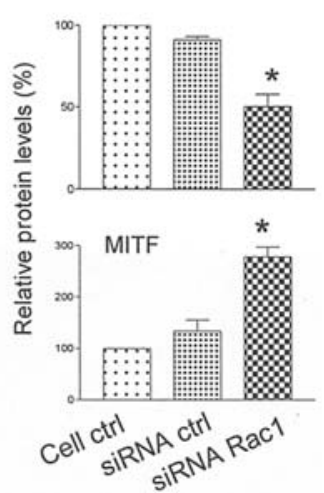

B

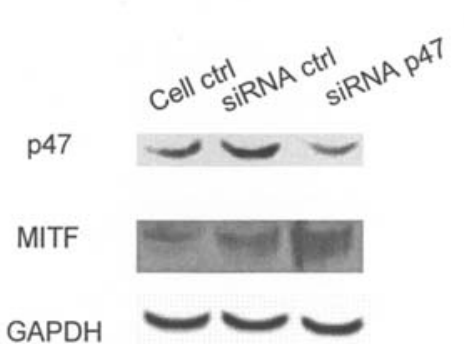

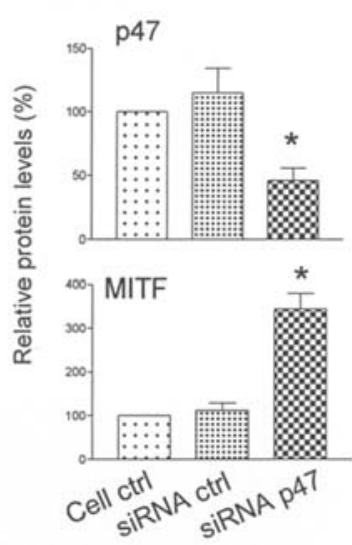

Figure 2. Western blot analysis of MITF in Rac1/p47 knockdown cells. B16 cells grown in 6-well plates were transfected with siRNA to Rac1 (A) /p47 (B) for $48 \mathrm{~h}$. GAPDH served as a loading control. Ctrl, control. * Significant difference compared with the control group, p<0.05.

A

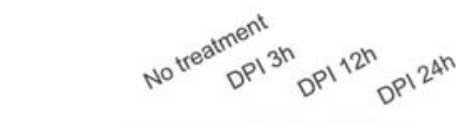

PCNA

GAPDH

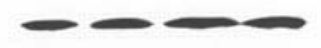

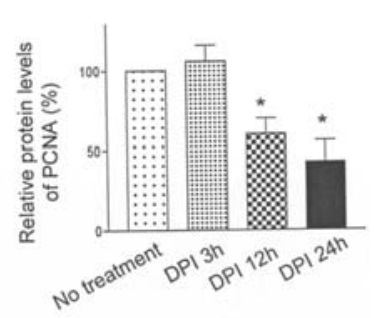

B
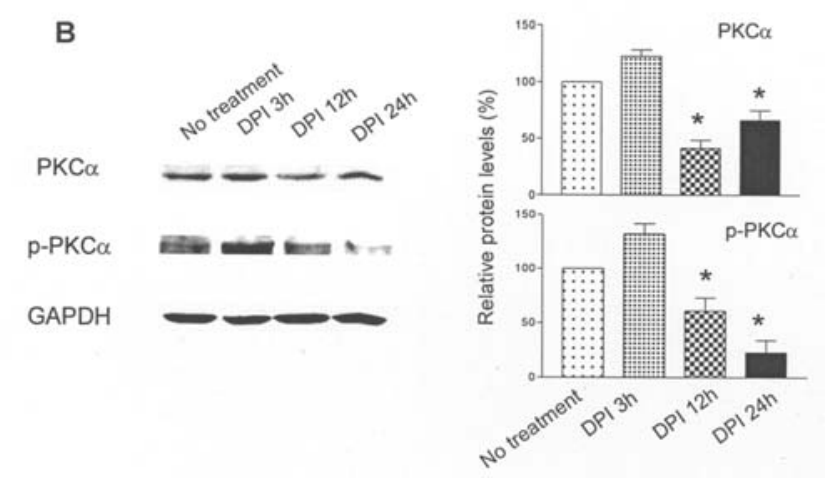

D

C

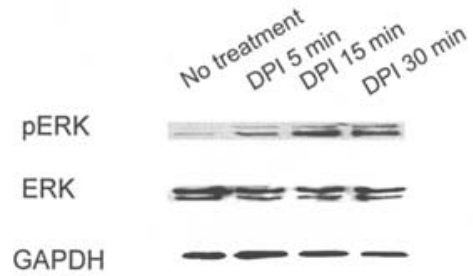

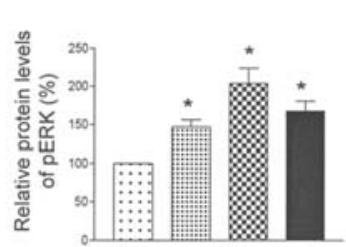

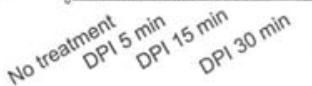

MITF

pERK
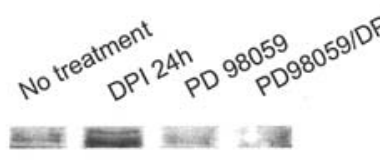

GAPDH

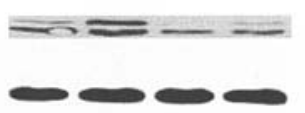

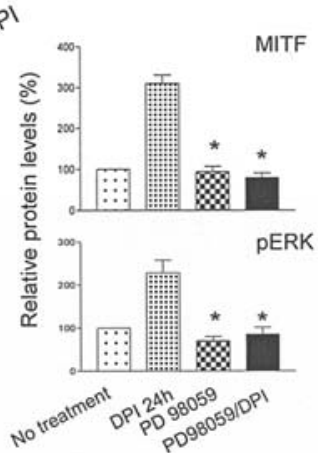

Figure 3. Mechanistic studies of the effects of inhibiting NOX activity. When cell growth reached $\sim 60 \%$ confluency, B16 cells were treated with $1 \mu \mathrm{M}$ DPI. Whole cell lysate was used for the studies. GAPDH served as a loading control. All the experiments were repeated at least three times and a representative result is shown. (A) Western blot analysis of PCNA. B16 cells were treated for 3, 12 or $24 \mathrm{~h}$. *Significant difference compared with no treatment group, $\mathrm{p}<0.05$. (B) Western blot analysis of PKC $\alpha$. ${ }^{*}$ Significant difference compared with no treatment group, $\mathrm{p}<0.05$. (C) Western analysis of pERK. B16 cells were treated for 5, 15 or $30 \mathrm{~min}$. *Significant difference compared with no treatment group, p<0.05. (D) Western analysis of MITF, pERK and PCNA. B16 cells were pretreated with $10 \mu \mathrm{M}$ PD98059 for $30 \mathrm{~min}$ followed by $1 \mu \mathrm{M}$ DPI treatment for $24 \mathrm{~h}$. ${ }^{*}$ Significant difference compared with DPI- $24 \mathrm{~h}$ group, p<0.05.

as an indictor of cell proliferation. A representative Western blot result is shown in Fig. 3A, which showed a time-dependent reduction of PCNA levels by DPI treatment. In melanoma cells, PKC $\alpha$ activation is typically associated with increased tumor cell proliferation, invasiveness and decreased differentiation (9). We then examined the protein levels of PKC $\alpha$ and its phosphorylated form after DPI treatment. As seen in a representative result (Fig. 3B), both levels of PKC $\alpha$ were decreased at 12 and $24 \mathrm{~h}$ after DPI treatment. Furthermore, studies suggest that factors contributing to melanogenesis can activate ERK (10). Since activation of
ERK could be a rapid event, we detected the protein levels of pERK within 30 min after DPI treatment. As seen in a representative result in Fig. 3C, DPI rapidly increased the levels of pERK 1 and pERK2 within 5 min, and the increase remained at 15 and $30 \mathrm{~min}$. We then detected how the inhibition of MAPK affected MITF expression, as seen in Fig. 3D, the MAPK inhibitor PD98059 suppressed the expression levels of pERK and MITF; which were induced by DPI.

p53, not PTEN, was affected by the inhibition of NADPH oxidase activity. Tumor suppressors also affect cell growth 


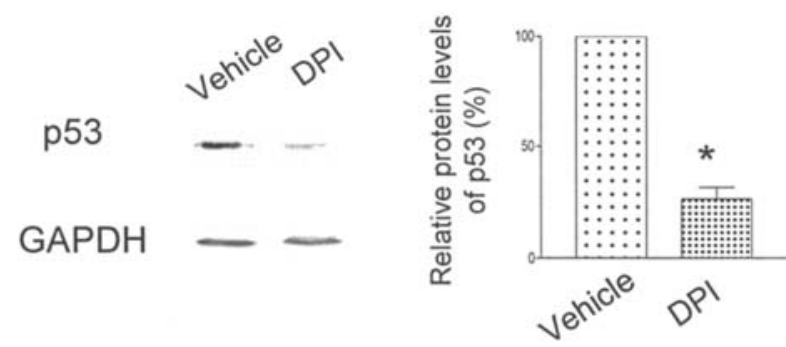

Figure 4. The effect of DPI on the expression of the tumor suppressors. A representative Western blot analysis of p53 is shown. B16 cells were treated with either Vehicle (0.01\% DMSO) or $1 \mu \mathrm{M}$ DPI for $24 \mathrm{~h}$. GAPDH served as a loading control. PTEN was undetectable (data not shown). *Significant difference compared with Vehicle control, $\mathrm{p}<0.05$

and differentiation in melanoma cells. The tumor suppressor PTEN has been suggested to be silenced, but not mutated in melanoma cells (11). We could not detect the expression of PTEN in untreated or DPI $(1 \mu \mathrm{M})$-treated B16 cells in a $24 \mathrm{~h}$ time course (data not shown); indicating that the inhibition of NOX activity may not induce PTEN expression. Another important tumor suppressor, p53, has been found to negatively contribute to cell differentiation in metastatic melanoma cells (12). We detected the expression of p53 after treatment with $1 \mu \mathrm{M}$ DPI for $24 \mathrm{~h}$. As shown in a representative result in Fig. 4, DPI suppressed the expression of p53.

\section{Discussion}

Oxidative stress has been implicated to play an important role in cancer development. Overexpression of antioxidant enzymes, especially manganese superoxide dismutase (MnSOD) reduces tumorigenesis in several human cancer cell lines and carcinogenesis in mouse models $(1,13)$. On the other hand, we previously demonstrated that inhibiting the activities of NADPH oxidase by DPI reduced oxidative stress, as indicated by decreased levels of protein carbonyls. This inhibition causes suppressed cell proliferation in a malignant skin keratinocyte (308) and a skin carcinogenesis mouse model (4), suggesting that targeting the source of ROS (e.g. NADPH oxidase) can be another choice for antioxidant therapy. Although malignant melanoma is the third most common dermatologic cancer, it is responsible for $80 \%$ of deaths from skin cancer. It has been suggested that ROS generated in an autocrine fashion by NOX may play a role in signaling malignant melanoma growth (3), which provides the rationale for this study. Our results demonstrated that the inhibition of NOX activity suppressed melanoma cell growth, which is consistent with the notion of the role of ROS in mediating melanoma cell proliferation.

Redox status has been recognized to play an important role in regulating cell differentiation (14). We observed a promotion in cell differentiation by inhibiting NOX activity, which is consistent with the reports in which overexpression of SOD in vitro promotes cancer cell differentiation $(8,15)$, but contradicts the results that show ROS generated by NOX are critical for muscle cell differentiation $(16,17)$. We suspect that ROS generates by NOX may play different roles between cancer cells and muscle cells in differentiation.
Melanoma, like many other cancer subtypes, has been observed to exhibit reversible defects in differentiation (18). Exiting the cell proliferation cycle is the first step for cell differentiation. As an important oncoprotein, protein kinase $\mathrm{C}$ (PKC) was the first to be identified as a contributing factor in skin tumorigenesis. In models of melanoma, PKC $\alpha$ activation is typically associated with increased tumor cell proliferation, invasiveness and decreased differentiation (9). Our results, demonstrating that the inhibition of NOX activity decreases the expression of PKC $\alpha$, is consistent with the role of PKC $\alpha$ in melanoma differentiation and further reveals that $\mathrm{PKC} \alpha$ may mediate ROS-induced cell growth in melanoma.

ERK activation is one important generic change in melanoma (19). Studies suggest that factors contributing to melanogenesis can activate ERK, and that the signal intensity and the timing of the ERK signal are important in deciding cell growth or differentiation (10). We observed that the increase in pERK expression was rapid (within 30 min after a DPI application), suggesting that ERK activation in DPI-induced melanoma differentiation is an early event. Decreases in NADPH oxidase subunits Rac1 and p47 expression by siRNA increased pERK levels (data not shown), confirming the direct role of NADPH oxidase in regulating ERK signaling. pERK can directly regulate MITF, a master transcription factor for melanocytic gene regulation (20). MAPK phosphorylation has been reported to directly activate MITF and to signal its degradation (21). Both events seem to exist in our model, since the MAPK inhibitor PD98059 slightly increased the levels of MITF, whereas it also blocked DPI-induced MITF expression. PD98059 did not suppress the expression of PCNA (data not shown), indicating that ERK signaling likely contributes to differentiation other than blocking proliferation in our model.

The tumor suppressor genes PTEN and p53 are important in melanoma development (19). It has been suggested that PTEN was silenced but not mutated in melanoma cells (11). Since PTEN appears essential in maintaining the balance among normal cell growth, differentiation, and malignancy (22), we performed Western blot analysis to detect the expression of PTEN in untreated and DPI-treated B16 cells. The protein levels of PTEN were undetectable; suggesting that PTEN does not play an important role in the DPI-induced events in melanoma B16 cells. The role of another important tumor suppressor, p53, has been well studied. For instance, it was concluded that high p53 expression in tumor cells is associated with a poorer prognosis in primary melanoma (23); p53 has also been found to negatively contribute to cell differentiation in metastatic melanoma cells (12). B16 melanoma cells are known to express wild-type p53 (24), and Western blot analysis demonstrated that there was endogenous expression of p53 in B16 cells. Decreased expression of p53 was observed when there was an increased level of melanin production; revealing that p53 may play a negative role in B16 melanoma differentiation. These results are consistent with our previous findings in malignant skin keratinocyte 308 cells, which showed that blocking NOX activity by DPI led to a reduction of p53 levels (4).

Taken together, our results demonstrate that the inhibition of NOX activity suppresses B16 melanoma cell proliferation and promotes cell differentiation. ROS generated by NADPH oxidase serves as an essential role in signaling melanoma 
growth and the enzyme could be a potential target for melanoma therapy.

\section{Acknowledgements}

The authors wish to thank Dr Daret St. Clair at the University of Kentucky for helpful discussions; Dr Stephen Pruett, Charlie Raver, Bing Cheng and Yan Li at LSU Health Sciences Center-Shreveport for their technical support. The research is supported by the Seed Grand from LSU Health Sciences Center-Shreveport.

\section{References}

1. Oberley LW: Mechanism of the tumor suppressive effect of MnSOD overexpression (Review). Biomed Pharmacother 59: 143-148, 2005.

2. Hoeng MT and Eichenfield LF: The rising incidence of melanoma in children and adolescents. Dermatol Nurs 12: 188-193, 2000

3. Brar SS, Kennedy TP, Sturrock AB, et al: An NAD(P)H oxidase regulates growth and transcription in melanoma cells. Am J Physiol Cell Physiol 282: C1212-C1224, 2002.

4. Zhao Y, Chaiswing L, Bakthavatchalu V, et al: Ras mutation promotes p53 activation and apoptosis of skin keratinocytes. Carcinogenesis 27: 1692-1698, 2006.

5. Cui XL and Douglas JG: Arachidonic acid activates c-jun Nterminal kinase through NADPH oxidase in rabbit proximal tubular epithelial cells. Proc Natl Acad Sci USA 94: 3771-3776, 1997.

6. Hakozaki T, Minwalla L, Zhuang J, et al: The effect of niacinamide on reducing cutaneous pigmentation and suppression of melanosome transfer. Br J Dermatol 147: 20-31, 2002.

7. St. Clair DK, Oberley TD, Muse KE, et al: Expression of manganese superoxide dismutase promotes cellular differentiation. Free Radic Biol Med 16: 275-282, 1994.

8. Zhao Y, Kiningham KK, Lin SM et al: Overexpression of MnSOD protects murine fibrosarcoma cells (FSa-II) from apoptosis and promotes a differentiation program upon treatment with 5-azacytidine: involvement of MAPK and NFkappaB pathways. Antioxid Redox Signal 3: 375-386, 2001.

9. Lahn MM and Sundell KL: The role of protein kinase C-alpha (PKC-alpha) in melanoma (Review). Melanoma Res 14: 85-89, 2004.
10. Smalley KS: A pivotal role for ERK in the oncogenic behaviour of malignant melanoma? (Review) Int J Cancer 104: 527-532, 2003.

11. Pollock PM, Walker GJ, Glendening JM, et al: PTEN inactivation is rare in melanoma tumours but occurs frequently in melanoma cell lines. Melanoma Res 12: 565-575, 2002.

12. Rauth S, Kichina J and Green A: Inhibition of growth and induction of differentiation of metastatic melanoma cells in vitro by genistein: chemosensitivity is regulated by cellular $\mathrm{p} 53 . \mathrm{Br} \mathrm{J}$ Cancer 75: 1559-1566, 1997.

13. St. Clair DK, Zhao Y, Chaiswing L, et al: Modulation of skin tumorigenesis by SOD (Review). Biomed Pharmacother 59: 209-214, 2005.

14. Smith J, Ladi E, Mayer-Proschel M, et al: Redox state is a central modulator of the balance between self-renewal and differentiation in a dividing glial precursor cell. Proc Natl Acad Sci USA 97: 10032-10037, 2000

15. Kinnula VL and Crapo JD: Superoxide dismutases in malignant cells and human tumors (Review). Free Radic Biol Med 36: 718-744, 2004.

16. Piao YJ, Seo YH, Hong F, et al: Nox 2 stimulates muscle differentiation via NF-kappaB/iNOS pathway. Free Radic Biol Med 38: 989-1001, 2005.

17. Sturrock A, Cahill B, Norman K, et al: Transforming growth factor-beta1 induces Nox4 $\mathrm{NAD}(\mathrm{P}) \mathrm{H}$ oxidase and reactive oxygen species-dependent proliferation in human pulmonary artery smooth muscle cells. Am J Physiol Lung Cell Mol Physiol 290: L661-L673, 2006.

18. Leszczyniecka M, Roberts T, Dent $\mathrm{P}$, et al: Differentiation therapy of human cancer: basic science and clinical applications (Review). Pharmacol Ther 90: 105-156, 2001.

19. Miller AJ and Mihm Jr MC: Melanoma. N Engl J Med 355: 51-65, 2006

20. Goding CR: Mitf from neural crest to melanoma: signal transduction and transcription in the melanocyte lineage. Genes Dev 14: 1712-1728, 2000.

21. Wu M, Hemesath TJ, Takemoto CM, et al: c-Kit triggers dual phosphorylations, which couple activation and degradation of the essential melanocyte factor Mi. Genes Dev 14: 301-312, 2000.

22. Yamada KM and Araki M: Tumor suppressor PTEN: modulator of cell signaling, growth, migration and apoptosis (Review). J Cell Sci 114: 2375-2382, 2001.

23. Ilmonen S, Hernberg M, Pyrhonen S, et al: Ki-67, Bcl-2 and p53 expression in primary and metastatic melanoma. Melanoma Res 15: 375-381, 2005.

24. Melnikova VO, Bolshakov SV, Walker C, et al: Genomic alterations in spontaneous and carcinogen-induced murine melanoma cell lines. Oncogene 23: 2347-2356, 2004. 